\title{
Farklı LEED Versiyonlarının İç Mekânlardaki Su ve Enerji Verimliliği Üzerindeki Etkileri
}

\author{
Dilara N. KESKINN ${ }^{1}$ (D), Deniz AKGÜL $L^{2}$ (i) \\ ${ }^{1}$ Marmara Üniversitesi, Göztepe Kampüsü, Fen Bilimleri Enstitüsü, Çevre Bilimleri Programı, Kadıköy, \\ Istanbul, Türkiye \\ ${ }^{2}$ Marmara Üniversitesi, Göztepe Kampüsü, Mühendislik Fakültesi, Çevre Mühendisliği Bölümü, Kadıköy, \\ Istanbul, Türkiye
}

\section{$\ddot{O} z$}

Doğal kaynakların hızla tüketildiği ve sera gazı emisyonlarının artarak küresel ısınma etkilerinin her geçen gün daha da görünür hale geldiği günümüzde, sürdürülebilirlik çalışmaları ile çevreye verilen tahribatın azaltılması hedeflenmektedir. Doğal kaynak kullanımı ve yüksek emisyon değerleri sebebiyle, inşaat sektörü bu anlamda acil önlem alması gereken sektörlerdendir. $\mathrm{Bu}$ kapsamda yeşil bina sertifikasyonları, inşaat sektöründeki sürdürülebilirlik uygulamalarını yönlendirmektedir. $\mathrm{Bu}$ sertifikasyonlar, güncel çevre sorunlarının çözümüne pozitif yönde etki edebilme amacı ile gerekli görüldükçe yenilenmektedirler. Bu çalı̧̧mada, dünyada en çok tercih edilen yeşil bina sertifikası olan Enerji ve Çevresel Tasarımda Liderlik (LEED)'in iç mekândaki su ve enerji verimliliği alt başlıklarında yapılan güncellemelerin su ve enerji tüketiminden kaynaklanan $\mathrm{CO}_{2}$ emisyonlarını nasıl etkilediği analiz edilmiştir. Bu kapsamda, 2009 yılına ait LEED versiyon 3 ile 2019 yllında yayınlanan güncel versiyon 4.1 arasındaki farklılıklar, versiyon 3 kapsamında sertifikalandırılmış örnek bir bina üzerindeki su ve enerji verimliliği analizleriyle ortaya konmuștur. Bu iki versiyon kapsamlı olarak incelendiğinde, iç mekândaki su verimliliği gereklilikleri üzerinde büyük güncellemeler olmamasına rağmen, yapılan değişikliklerin projeleri su tüketimini azaltma, ya da alternatif su kaynaklarını kullanma konusunda teşvik ettiği belirlenmiștir. Bu sayede hem su kaynaklarının korunabileceği, hem de su tüketiminin azaltılmasıyla birlikte su arıtımı, dağıtımı ve atık suların bertarafindan kaynaklanan $\mathrm{CO}_{2}$ salımlarını \% 10,5 oranında azaltılabileceği tespit edilmiştir. Enerji verimliliği açısından ise versiyon 3 'te takip edilen ASHRAE 90.1-2007 ile güncel versiyonda takip edilen ASHRAE 90.1-2016 arasındaki farklılıklar sayesinde, aynı verimlilik oranının sağlanması için yapılacak uygulamalarla $\mathrm{CO}_{2}$ salımının $\% 16,6$ oranında azaltılabileceği ortaya konmuş̧ur.

Anahtar Kelimeler: Yeşil Bina, LEED, Su Verimliliği, Enerji Verimliliği, $\mathrm{CO}_{2}$ Emisyonu, Bina Enerji Modellemesi

\begin{abstract}
Nowadays, while natural resources are being depleted rapidly and the effects of global warming has become more distinct with the increasing greenhouse gas (GHG) emissions, it is aimed to prevent environmental degradation through sustainability studies. Due to the high consumption of natural sources and GHG emissions, construction sector is one those that should act immediately. In this context, green building certifications lead sustainability practices in the construction industry. These certifications are updated as necessary in order to provide solution for current environmental problems. In this study, how $\mathrm{CO}_{2}$ emissions caused by water and energy consumption are affected by the updates in indoor water and energy efficiency subtitles of Leadership in Energy and Environmental Design (LEED), which is the most preferred green building certification in the world, was analyzed. In this context, the differences between LEED v3 (published in 2009) and v4.1 (published in 2019) were revealed by conducting water and energy efficiency analyzes on a sample building certified under version 3 . When these two versions are examined side by side, although there are no major updates on indoor water efficiency requirements, it has been shown that, the changes lead projects to either decrease the water use or use alternative water resources. In this way, it has been determined that, both water resources can be protected and as a result of reducing water consumption, $\mathrm{CO}_{2}$ emissions caused by water treatment, distribution and disposal of wastewater can be reduced by $10.5 \%$. It was found that, thanks to the differences between ASHRAE 90.1-2007 (v3) and ASHRAE 90.1-2016 (v4.1), applications to be carried out to provide the same efficiency may reduce $\mathrm{CO}_{2}$ emissions by $16.6 \%$.
\end{abstract}

Keywords: Green Building, LEED, Water Efficiency, Energy Efficiency, $\mathrm{CO}_{2}$ Emissions, Building Energy Modelling

\section{GİRIŞ}

Dünyada nüfus artışı ve sanayileşmeyle birlikte fosil yakıt kullanımının artması, kentleşme, kentleşme sürecinde orman alanlarının ve doğal kaynakların tahribatı ile bilinçsiz arazi kullanımı atmosferdeki sera gazı emisyonlarının 
artmasına neden olmuştur. Sera gazı emisyonunun artması, sıcaklık değerlerindeki artışın, dolayısıyla iklim değişikliğinin en önemli sebeplerindendir [1]. Sıcaklık artışı ve atmosferdeki sera gazı konsantrasyonlarının yükselmesi ekolojik dengeyi de etkilemektedir. Yerkürenin aşırı ısınmaya başlaması, buzulların erimesi, sel, kuraklık ve su kıtlığı riskleri gibi bir takım ekolojik dengesizliklerin ortaya çıkması küresel ısınmanın sonuçlarındandır [2, 3].

Küresel iklim değişikliğiyle birlikte önemi gitgide artan sürdürülebilirlik kavramı, beraberinde kaynakların korunması amacıyla çeşitli uygulamalar getirmiştir. Bunlardan biri de özellikle inşaat sektöründe doğal kaynakların hızla tüketiminin önüne geçmek amacıyla oluşturulan "Yeşil Bina" kavramıdır. İnşaat sektörü, doğal kaynakların tüketimi açısından önemli bir paya sahiptir. Günümüzde yapı sektörü doğadan elde edilen ham maddenin \%50'sini, küresel enerjinin \%40'ını ve suyun \%16'sını tüketirken, oluşan atıkların da \%50'sinden sorumludur [4]. Kaynak korumasını amaçlayan "Yeşil Bina" kavramı da bu noktada önem arz etmektedir. İnşaat sektöründe enerji ve su verimliliğine önem veren, malzeme seçimleriyle hem kullanıcıların sağlığını göz önüne alıp hem de çevreye verilen olumsuz etkiyi azaltan, arazi seçimi ve inşaat yapımı sırasındaki uygulamalara müdahale ederek doğal çevreyi koruyan uygulamalar "Yeşil Bina" kavramı çerçevesinde değerlendirilmektedir.

Yeşil Bina kavramıyla ilgili olarak, farklı ülkelerde farklı sertifikasyon sistemleri oluşturulmuştur. Fakat dünya çapında en çok tercih edilen yeşil bina sertifikasyon sistemi 124.428 kayıtlı projesiyle Enerji ve Çevresel Tasarımda Liderlik (LEED) sertifikasıdır [5,6]. LEED sertifikası 1993'te sürdürülebilirlik alanında çalışmalar yapmak amacıyla kurulan Amerikan Yeşil Bina Konseyi (USGBC) tarafindan 1998 yılında yayınlanmıştır [7]. LEED sertifikası, yeni yapılacak binalarda, iç mekânlarda, mevcut yapılarda, mahallelerde ve düşük-orta katlı konut binalarında takip edilebilen bir sertifikasyon türüdür [8].

Küresel 1sınmanın etkisinin giderek artması, LEED'in sertifikasyon için gerekli olan koşulları başlangıçtan bu yana sürekli olarak güncelleyerek daha sıkı hale getirmesine neden olmuştur. 1998 yılında yayınlanan ilk versiyon v1 oluşturulmuş ve ardından 2000, 2002, 2005, 2009, 2013 yillarında sirasiyla v2, v2.1, v2.2, v3 ve v4 yayınlanmıştır. 2016 yılına kadar v3 projelerinin sisteme kayıtları devam etmiştir fakat 2016 yılından sonra tüm proje kayıtları versiyon 4 kapsamında yapılmıştır $[9,10]$. Aralık 2018 itibariyle de versiyon 4 üzerinde güncellemeler yapılarak v4.1 Beta yayınlanmış, Ocak 2019 itibariyle v4.1 kullanıma açılmıştır [11].

LEED sertifikasında binalar 110 puan üzerinden değerlendirilmekte ve toplanan puan sonucuna göre sertifika seviyesi Sertifikalı, Gümüş, Altın ve Platin olarak derecelendirilmektedir. $\mathrm{Bu}$ sertifikasyon türünde, sertifikayı alabilmek için yapılması zorunlu tutulan gereklilikler "Ön Koşul”, puan toplanılarak sertifika seviyesinin ne olacağının belirlenmesine katkı sağlayan gereklilikler ise "Kredi" olarak adlandırılmaktadır. LEED Yeni Binalar ve Majör Renovasyonlar (BD+C:NC) v4.1 sertifikası 9 ana kategoriden oluşmaktadır. Bunlar; bütünleşik süreç yönetimi, konum ve ulaşım, sürdürülebilir araziler, su verimliliği, enerji ve atmosfer, malzeme ve kaynaklar, iç mekân kalitesi, tasarımda yenilik ve bölgesel öncelik kategorileridir. Enerji ve Atmosfer kategorisi altındaki enerji performansının optimizasyonu kredisi 18 puan ile tüm LEED kredileri arasında en yüksek puan değerine sahip kredidir. Su Verimliliği kategorisi altındaki iç mekânda su kullanımının azaltılması kredisi ise 6 puan ile toplam puana etkisi açısından ikinci sırada önem arz eden kredilerdendir [12].

Bu çalışmada, su ve enerji kaynaklarının tüketimi ile bu tüketimin sebep olduğu çevresel etkileri azaltmayı hedefleyen, enerji performansının optimizasyonu ve iç mekânda su kullanımının azaltılması kredilerindeki güncellemeler LEED $\mathrm{BD}+\mathrm{C} \quad \mathrm{v} 3$ ile v4.1 için karşılaştırmalı olarak analiz edilmiştir. $\mathrm{Bu}$ analizlerle birlikte, LEED'in yönlendirdiği şekilde enerji ve su tüketimleri elde edildiğinde $\mathrm{CO}_{2}$ salımlarının ne yönde etkilendiği ortaya konmuştur. Çalışmamız, LEED Yeni Binalar ve Majör Renovasyonlar kategorisi altında uygulamaya 2019 yılında geçmiş olan versiyon 4.1 ile ilgili yapılacak ilk akademik çalışmalardan olma özelliği taşımaktadır. Özellikle yeşil bina sertifikasyonu kapsamında yapılan bilimsel çalışmalarda genellikle LEED, BREEAM, DGNB ve GSAS gibi farklı sertifikasyon türleri arasındaki farklılıklar karşılaştırılmıştır. Bu çalışmaların bir kısmında su ve enerji verimliliği üzerinde de durulmuştur [7, 13, 14, 15,]. Mevcut literatürden farklı olarak çalışmamızda ilk defa LEED BD+C: NC'nin en güncel versiyonu v4.1 ile 2009 yılına ait LEED v3, enerji ve su verimliliği konularında karşılaştırmalı olarak ele alınmıştır.

\section{MATERYAL VE YÖNTEM}

Çalışmamız kapsamında öncelikle süreç şemasında (Şekil 1) görüldüğü üzere, enerji ve su kullanım analizlerinin yapılabileceği örnek bir bina seçilmiştir. $\mathrm{Bu}$ binaya ait veriler mimari, mekanik, elektrik projelerinden ve bina kayıtlarından tedarik edilmiştir. Ardından, LEED BD+C:NC gerekliliklerinin v3 ile v4.1 arasındaki farklılıkları tespit edilerek örnek binanın iç mekândaki su ve enerji verimliliği analizleri gerçekleştirilmiştir. Su verimliliği analizi için Microsoft Excel, enerji modellemesi için Carrier Hap programları kullanılmıştır. 


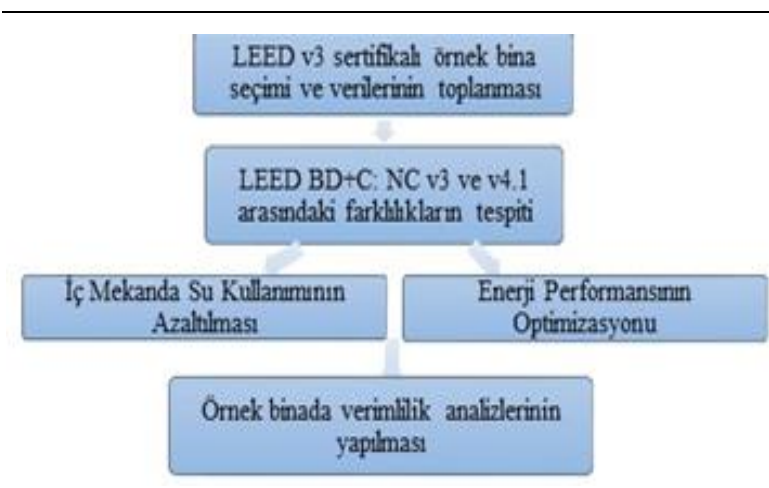

Şekil 1. Çalışmaya ait süreç şeması

\section{1. Çalışma Kapsamında Seçilen Örnek Bina} Çalışma kapsamında LEED v3 ve LEED v4.1 arasındaki farklılıkların değerlendirilebilmesi için örnek bina olarak LEED $\mathrm{BD}+\mathrm{C}$ : $\mathrm{NC}$ v3'ten sertifikalandırılmış bir bina tercih edilmiştir. Bunun için birçok kredide başarı sağlamış ve Platin seviyesinde sertifika almaya hak kazanmış, 3 katlı, 400 $\mathrm{m}^{2}$ 'lik orta ölçekli bir ofis binası seçilmiştir. Bu bina, büyük ölçekte bir renovasyon ile yapıldığı için LEED Yeni Binalar ve Majör Renovasyonlar kategorisi altında değerlendirilmiştir.

Bina İstanbul'da yer aldığ için ASHRAE 90.1-2016'ya göre 3A iklim bölgesinde, ASHRAE 90.1-2007'ye göre 4A iklim bölgesinde yer almaktadır. Buradaki tanımlamaya göre, iklim bölgeleri 0 ile 8 arasındadır ve 0 en sıcak, 8 en soğuk bölgeleri göstermektedir. Nem alt bölgeleri ise A (nemli), B (kuru) veya C (deniz) harfleriyle belirtilmektedir [16]. Proje binasında 3 açık ofis, 3 kapalı ofis, 2 toplantı odası, 3 tuvalet, 1 mescit, 1 yemekhane ve 1 garaj bulunmaktadır. Mekanik olarak şartlandırılmamış garaj, mescit ve tuvaletler $41 \mathrm{~m}^{2}$ yi oluşturmaktadır. Kalan diğer mahaller ise şartlandırılmıştır ve $359 \mathrm{~m}^{2}$ 'lik alana sahiptir.

Çalışma kapsamında değerlendirilen binanın başvurduğu diğer LEED kredileri gibi, enerji performansının optimizasyonu ve iç mekânda su kullanımının azaltılması kredileri 2013 yılında USGBC tarafindan onaylanmış ve bina tüm çalışmalarıyla birlikte LEED Platin sertifika almaya hak kazanmıştır. 2013 y1lındaki analiz sonuçlarına göre, ASHRAE 90.1.2007 standardı baz alınarak yapılan enerji verimliliği analizinde, binada PV panel kullanımıyla birlikte $\% 51$ oranında enerji verimliliği sağlanmaktadır. İç mekândaki su verimliliğgi analizlerinde ise bina toplam $\% 43$ oranında su verimliliğine sahiptir.

\subsection{LEED BD+C: NC v3 ve v4.1 Kapsamında İç Mekânda Su Verimliliği ve Enerji Performansının Optimizasyonu Kredilerindeki Farklılıklar}

Çalışmamızda versiyonlar arasındaki farkların, kaynak kullanımı üzerindeki etkilerinin irdelenebilmesi için öncelikle LEED v3 ile v4.1 gereklilikleri ve analiz yöntemleri arasındaki farkl1lıklar incelenmiştir. $\mathrm{Bu}$ sayede analizler, ilgili versiyonda belirtilen standartlar ve yöntemler baz alınarak tamamlanmıştır.

İç mekânda su kullanımının azaltılması ve enerji performansının optimizasyonu kredileri kapsamında, v3 ile v4.1 arasında analiz sonuçlarına göre alınabilen puanlarda değişiklikler olmuştur. İç mekânda su kullanımının azaltılması kredisinden $\mathrm{v}$ ' te maksimum 4 puan alınabilirken v4.1'de bu 6 puana kadar yükselmiştir. Enerji performansının optimizasyonu kredisinde ise $\mathrm{v} 4.1$ 'de enerji verimliliği, kredi gerekliliğinin bir kısmını oluşturmakta, diğer kısmında ise sera gazı emisyonu sonucu puan almada etkin rol oynamaktadır. Dolayısıyla enerji verimliliği açısından bina enerji modellemesine göre \%44 verimlilik sağlanıyorsa, v3'te en yüksek puan olan 19 puan alınabiliyorken; $\mathrm{v} 4.1$ ' de bu analizden 9 puan alınabilmekte ve kalan diğer 9 puanı sera gazı emisyon sonucu belirlemektedir $[12,17]$.

Çalışma kapsamında ele alınan enerji performansının optimizasyonu kredisinde, bina enerji modellemesi yapılarak binadaki enerji verimliliği ortaya koyulmaktadır. V4.1'de bir yenilik olarak, binanın enerji kullanımı nedeni ile sebep olduğu sera gazı emisyonu da ikinci bir opsiyon olarak incelenmekte ve bu oran ne kadar az olursa o miktarda puan durumuna etki etmektedir. Dolayısıyla v4.1 değerlendirmesi yapılırken binanın enerji verimliliğinin yanı sıra sera gazı emisyon faktörü de ortaya konmaktadır. İç mekanda su kullanımının azaltılması kredisinde, v4.1'de binada kullanılan ve su tüketen beyaz eşyalarda bazı sertifika türleri aranmaktadır fakat bu cihazlar su tüketimi analizine dahil edilmemektedir.

\subsection{1. İç mekânda su kullanımının azaltılması kredisindeki güncellemeler}

USGBC'nin, iç mekandaki su verimliliği analizlerini gerçekleştirilmesi için baz aldığ 5 temel parametre vardır. Bunlar;

- Bina kullanıcı ile ziyaretçi sayıları,

- Binanın işletildiği gün sayısı,

- LEED'in EPAct (Enerji Politika Yasası) 1992 standartlarınca belirlenen; armatürde/rezervuarda olması gereken maksimum su tüketim değerleri (baz değerler),

- Kullanıcı tür ve cinsiyetlerine göre farklılık gösteren armatür kullanım sıklıkları,

- Proje alanında kullanılan armatür ve rezervuarların su tüketim değerleridir.

Bina için seçilen vitrifiye armatürler/rezervuarların su tüketim değerleri ile yukarıdaki parametreler dikkate alınarak bir yılda binada kaç litre su tüketileceği hesaplanmaktadır. Projedeki seçilen armatürlerle oluşan toplam su tüketiminin, baz değerler (Tablo 1) kullanılarak hesaplanan su tüketim miktarına oranı, binadaki iç mekan su verimliliği oranını ortaya koymaktadır [17]. Bu sebeple, yukarıda belirtilen 
parametrelerdeki herhangi bir değişim, toplam su verimliliği oranının değişmesine sebep olacaktır.

Tablo 1. LEED'in EPAct (Enerji Politika Yasası) 1992 standartlarına uygun olarak hazırladığı, armatürde/rezervuarda olması gereken maksimum su tüketim değerleri (baz değerler)

\begin{tabular}{|c|c|c|}
\hline $\begin{array}{c}\text { Armatür } \\
\text { Tipi }\end{array}$ & $\begin{array}{l}\text { Baz değer } \\
\text { (v3 ve v4.1) }\end{array}$ & Kullanım süresi (saniye) \\
\hline Rezervuar & 6 litre/basım & - \\
\hline Pisuar & $\begin{array}{c}3,8 \\
\text { litre/basım }\end{array}$ & - \\
\hline $\begin{array}{c}\text { Ortak } \\
\text { lavabo } \\
\text { armatürü }\end{array}$ & $\begin{array}{c}\text { v3'te } \\
\text { fotoselli için } \\
\text { baz değer 4,7 } \\
\text { litre/dakika; } \\
\text { diğerleri 1,9 } \\
\text { litre/dakika } \\
\text { (415 kPa } \\
\text { basıçta) }\end{array}$ & $\begin{array}{c}30 \text { (v3'te fotoselli } \\
\text { armatürler } 12 \text { saniye } \\
\text { olarak } \\
\text { değerlendirilmektedir.) }\end{array}$ \\
\hline Duş & $\begin{array}{c}\text { 9,5 litre/ } \\
\text { dakika (550 } \\
\text { kPa basıçta) }\end{array}$ & 300 \\
\hline $\begin{array}{c}\text { Evye } \\
\text { bataryası }\end{array}$ & $\begin{array}{c}8,3 \text { litre/ } \\
\text { dakika (415 } \\
\text { kPa basıçta) }\end{array}$ & 15 \\
\hline
\end{tabular}

V3 ve v4.1 hesaplama yöntemi arasındaki dikkat çekici farklılık fotoselli lavabo armatürü tercihinin verimlilik hesaplarındaki etkisinin kaldırılmış olması ve tüm lavabo armatürlerinin 30 saniyelik kullanım üzerinden değerlendirilmesidir. Dolayısıyla v4.1'de lavabo armatürlerinin fotoselli olup olmamasının bir etkisi bulunmamakta ve tüm ortak kullanım lavabo armatürleri 30 saniyelik kullanım üzerinden hesaplanmaktadir. V3'te ise normal lavabo armatürlerinin su tüketimi 30 saniye üzerinden, fotoselli armatürlerin su tüketimi ise 12 saniye üzerinden hesaplanmaktadır [12,17].

\subsubsection{Enerji performansinın optimizasyonu kredisindeki güncellemeler}

Enerji performansının optimizasyonu kredisi üç opsiyondan oluşmaktadır. Fakat bu opsiyonlardan enerji verimlilik oranının artırılmasını ve $\mathrm{CO}_{2}$ salımlarının azaltılmasını yönlendiren, ayrıca en fazla puan getirisi olan Bina Enerji Simülasyonu; USGBC tarafindan binalarda tasarım sırasında yönlendirici olması ve daha enerji verimli binalar yapılması amacıyla önerilmektedir. Çalışma binasında da LEED v3 sertifikası alınırken bu opsiyon takip edilmiş ve ASHRAE Standard 90.1-2007 kullanılmıştır.

Enerji verimliliği hesaplarında LEED v3' te ASHRAE Standard 90.1-2007 kullanılırken, v4.1'de verimlilik hesaplarının ASHRAE Standard 90.1-2016'da tüm mekanik bileşenler için verilen baz değerlere göre yapılması gerekmektedir $[12,17]$. Enerji verimliliği analizinde proje binası, ASHRAE standardının baz değerlerine göre oluşturulmuş, aynı koşullara sahip bir bina ile kiyaslanmakta ve bu baz binaya göre ne kadar enerji verimli olduğu ortaya konmaktadır. ASHRAE standardındaki her bir değişiklik, o standarda göre yapılan enerji verimliliği analizinin sonucunu direkt olarak etkilemektedir. Bu sebeple ASHRAE 90.1-2007 ve 2016' da verilen baz değerler analiz edilmiş ve Tablo 2'de her iki ASHRAE standardına ait baz değerler sunulmuştur.

Bu kredide v4.1 ile gelen değişikliklerden biri; yalnızca binanın enerji verimliliği değil, bu verimliliğin sağladığı sera gazı emisyon oranının da krediden alınacak puanı belirlemesidir.

LEED v3'te enerji verimliliği oranı (EV) denklem (1) deki gibi hesaplanmaktadır.

$\mathrm{EV}=\frac{(B B E T-C, B E T)}{B B E T} x 100$

BBET baz binadaki enerji tüketim maliyeti, ÇBET ise çalışma binasındaki enerji tüketim maliyetidir.

Fakat v4.1'de enerji verimliliği sonucunu ortaya koymak için gerekli olan hesap yöntemi değiştirilmiştir. LEED v4.1'e göre enerji verimliliği hesabı için ASHRAE 90.1.2016 Ek G'deki performans derecelendirme yöntemi kullanılmaya başlanmıştır (Eşitlik 2-4).

$$
\begin{aligned}
& E V=1-(P C I / P C I t) \\
& P C I=C ̧ B E F / B B E F \\
& P C I t=(B B U E C+B P F \times B B R E C) / B B P
\end{aligned}
$$

PCI Binadaki enerji tüketiminin maliyet endeksi, ÇBEF çalışma binasının enerji performansı, BBEF baz binanın enerji performansı, PCIt bina için hedeflenen enerji tüketim maliyet endeksi, BBUEC baz binadaki kontrolsüz enerji maliyeti (priz yükleri), BBREC baz binadaki kontrollü enerji maliyeti (diğer enerji tüketim kollar1), BPF binanın performans faktörüdür. BPF, ASHARE 90.1 2016'da belirtilen binanın iklim zonu ve bina türüne göre belirlenmektedir ve çalışma binası için 0,6'dır. BBP ise baz binadaki enerji tüketim performansıdir.

LEED v4.1'de sera gazı salım oranı hesaplanırken de Eşitlik 2, 3 ve 4'teki formüller kullanılmıştır. Yalnızca verimlilikte kullanılan maliyet kalemleri $\mathrm{CO}_{2}$ emisyon eşleniğiyle değiştirilmiştir.

\subsection{Su ve Enerji Verimliliği Analizi İçin Girdilerin Belirlenmesi}

$\mathrm{Su}$ verimliliği analizi için öncelikle binadaki günlük kullanıcı sayısı ve binanın kaç gün kullanıldı̆̆ı bilgisi firma tarafindan edinilmiştir. Yılda 260 gün çalışılan firmada günlük ortalama 37 çalışan ve 6 ziyaretçi 
bulunmaktadır. İç mekânda kullanılan vitrifiye armatürler ile rezervuarların su tüketim bilgileri, hangi kullanıcıların hangi armatür ve rezervuarı kullandığı bilgisi, kullanıcı sayıları ve kullanım günüyle birlikte analiz girdilerini oluşturmaktadır.

Çalışma kapsamında enerji modellemesi yapılırken ise ASHRAE 90.1 Ek G'de yer alan simülasyon gereklilikleri ile binanın tasarımına ait veriler dikkate alınmıştır ve simülasyon için Carrier HAP yazılımı kullanılmıştır. Carrier HAP'ta bina modellenirken girdi olarak her bir mahal için alan bilgisi, havalandırma debileri, kullanıcı sayıları ve bina kullanımına ait zaman çizelgesi oluşturulmaktadır. Bina tasarımına bağlı olarak pencere, duvar alanları ile bunların 1s1 yalıtım katsayıları belirlenmiştir. Binadaki HVAC sistemleri tasarıma uygun olarak simülasyon programında oluşturulmuş, seçilen aydınlatma armatürlerinin aydınlatma güç yoğunlukları (LPD) mahal bazında hesaplanmıştır. Binadaki proses yükleri de ayrı bir girdi kalemini oluşturmaktadır. Enerji verimliliği oranı tüketilen elektriğin maliyet olarak baz bina ile karşılaştırılmasıyla ortaya konduğu için elektriğin birim fiyatı $0,15 \$ / \mathrm{kWh}$ olarak alınmıştır. Carrier HAP programında maliyet dolar bazında hesaplandığı için elektriğin birim fiyatı çalışmanın yapıldığı tarihteki güncel kur baz alınarak dolara çevrilmiştir [18].

Carrier HAP programında, proje binasının girdileri simülasyon için belirtildikten sonra bu girdiler ASHRAE 90.1 baz değerleriyle değiştirilmiştir. Binanın yönelişinin de enerji tüketimine etkisi olduğu için, ASHRAE değerleriyle oluşturulan baz bina $90^{\circ}$, $180^{\circ}$ ve $270^{\circ}$ döndürülerek baz binadaki ortalama enerji tüketimi hesaplanmıştır. Bu ortalaması alınmış baz bina ile tasarım binasının elektrik tüketim değeri arasındaki oran, enerji verimlilik oranını vermektedir. V3'de ASHRAE 90.1-2007, v4.1'de ASHRAE 90.1-2016 kullanıldığı için, baz değerlerde farklılıklar bulunmaktadır. Tasarım binasının girdileri ile her iki versiyona ait baz değerler Tablo 2'de belirtilmiştir.

Tablo2. Carrier HAP programı için enerji modellemesi girdileri

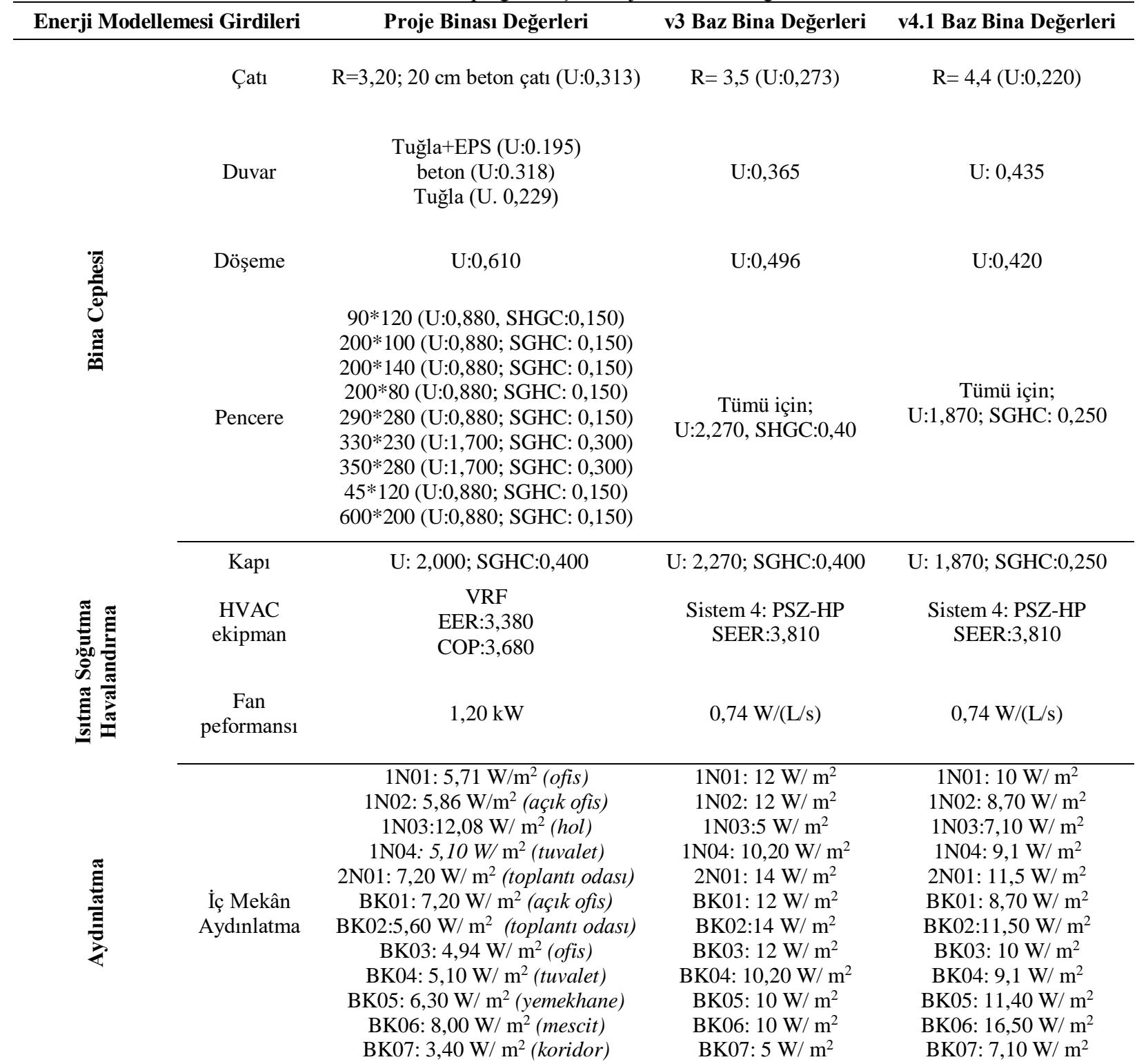




\begin{tabular}{|c|c|c|c|c|}
\hline & & $\begin{array}{c}\text { ZK01:7,65 W/ } \mathrm{m}^{2} \text { (açık ofis) } \\
\text { ZK02: 5,80 W/ }{ }^{2} \text { (ofis) } \\
\text { ZK03: } 12,00 \mathrm{~W} / \mathrm{m}^{2} \text { (giriş bekleme) } \\
\text { ZK04: 5,10 W/ m² (tuvalet) } \\
\text { ZK05: 3,40 W/ m² (koridor) }\end{array}$ & $\begin{array}{c}\text { ZK01:12 W/ m² } \\
\text { ZK02:12 W/ m² } \\
\text { ZK03: } 5 \mathrm{~W} / \mathrm{m}^{2} \\
\text { ZK04: } 10,20 \mathrm{~W} / \mathrm{m}^{2} \\
\text { ZK05: } 6,80 \mathrm{~W} / \mathrm{m}^{2}\end{array}$ & $\begin{array}{l}\text { ZK01:8,70 W/ m² } \\
\text { ZK02:10 W/ m² } \\
\text { ZK03:7,10 W/ m² } \\
\text { ZK04: } 9,1 \mathrm{~W} / \mathrm{m}^{2} \\
\text { ZK05: } 7,10 \mathrm{~W} / \mathrm{m}^{2}\end{array}$ \\
\hline & $\begin{array}{c}\text { Dış } \\
\text { Aydınlatma }\end{array}$ & $0,5 \mathrm{~kW}$ & $0,7 \mathrm{~kW}$ & $0,7 \mathrm{~kW}$ \\
\hline 실 & & $9,6 \mathrm{~kW}$ & $9,6 \mathrm{~kW}$ & $9,6 \mathrm{~kW}$ \\
\hline 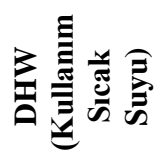 & & $4 \mathrm{~kW}$ & $6 \mathrm{~kW}$ & $6 \mathrm{~kW}$ \\
\hline
\end{tabular}

PV Panel: 9610,4 kW yıllık enerji üretimi

U: Isı İletim Katsayısı (W/m2·K), R: Isıl Direnç ( $\left.\mathrm{m}^{2} \mathrm{~K} / \mathrm{W}\right)$, SHGC: Güneş Enerjisi Toplam Geçirgenlik, EER: Enerji Verimlilik Oranı, COP: Performans Katsayısi, PSZ-HP: Isı Pompalı Paket Tip Rooftop

Bina cephesi kapsamında pencere, duvar, zemin, çatı ve kapı özellikleri dikkate alınmıştır. Çalışma binasında $\% 39$ cam-duvar oranı vardır. Bina cephesine ait bileşenlerin baz değerleri için ASHRAE 90.1-2007 ve ASHRAE 90.1-2016'daki iklim zonuna göre "Bina Cephe Gerekliliklerinde" belirtilen veriler kullanılmıştır. HVAC ekipmanları kapsamında çalışma binasında VRF sistemi kullanılmışken, ASHRAE 90.12007 ve ASHRAE 90.1-2016'da bu bina için Sistem 4; yani 1S1 pompalı paket tip rooftop önerilmektedir. ASHRAE'de baz bina için sistem belirlenirken v4.1'de mevcut binanın $\mathrm{m}^{2}$ 'si, kat yüksekliği, iklim zonu dikkate alınmakta; v3'te ise iklim zonu yerine çalışma binası enerji tüketim türü dikkate alınmaktadır. Havalandırma ekipmanı kapsamında proje binasında HRV sistemi bulunmaktadır. ASHRAE 90.1-2007'ye göre yapılan v3 enerji modellemesinde havalandırma oranları model girdisi değilken v4.1'te girdi olarak yer almıştır.

Projede bulunan aydınlatma armatürlerine ait Aydınlatma Gücü Yoğunluk (LPD) değerleri çalışma binasına ait aydınlatma planlarından alınmıştır. Baz değerler için ise ASHRAE 90.1 Tablo 9.6.1'de yer alan, her mahal için ayrı ayrı belirlenmiş olan LPD değerleri kullanılmıştır. İç mekândaki armatürlerin hafta içi ortalama olarak kış aylarında 6 saat, yaz aylarında 4 saat kullanıldığı dikkate alınmış, dış mekân armatürlerinin ise haftanın her günü 12 saat çalışması modelleme girdilerini oluşturmuştur.

Priz yükleri olarak mutfak ekipmanları, pompalar, ofis bilgisayarları çalışma binası ve baz binalarda aynı miktarda, toplam 9,6 kW değerinde alınmıştır. Kullanım sıcak suyu için modellemede girdiler belirlenirken dört ay boyunca kullanım suyu 1sitması için enerji tüketiminin olmayacağı hesaba katılmıştır. Bunun sebebi projede kullanilan hava kaynaklı 1s1 pompası, soğutmada atık 1sı ürettiğinden; bu atık 1s1, kullanım suyu ısıtması için kullanılmaktadır. Bu bina için soğutma mevsimi dört ay olduğundan bu dört ay kullanım suyu 1sitmasında enerji tüketimi olmayacaktır.

Tüm bunlara ek olarak proje binasında enerji verimliliğine etki edecek miktarda PV panel ile yıllık 9610,4 kW enerji üretimi mevcuttur.

\section{BULGULAR VE TARTIŞMA}

\section{1. İç Mekândaki Su Kullanımının Azaltılması}

İç mekândaki su verimliliği hesaplanırken, kullanıcı gruplarının türü dolayısıyla belirlenen kullanım sıklıkları, süreleri, kullandıkları armatürlerin debileri dikkate alınmıştır. Yapılan su verimliliği analizlerine göre fotoselli lavabo armatür kullanım süresi LEED v3'te 12 saniye olarak alınırken, LEED v4.1'de fotoselli armatürler de dahil tüm ortak lavabo armatürlerinin 30 saniyelik kullanım süresi üzerinden değerlendirilmesi, fotoselli armatür tercihlerinin su verimliliği açısından önemini kaybetmesine neden olmuştur. Şekil 2'de yillık olarak sifon ve armatürlerdeki toplam su tüketimleri v3 ile v4.1 hesap yöntemine göre ayrı ayrı belirlenmiştir. Pisuvar ve rezervuar için kullanılan su miktarı aynı kalırken, lavabo ve duşlardaki su tüketim miktarının v4.1'de v3'e göre daha fazla olduğu görülmektedir. Bunun sebebi güncel LEED versiyonunda fotoselli armatürler ile ilgili hesaplama yönteminin değişmesidir. $\mathrm{Bu}$ durum, dolayısıyla toplam su verimliliği oranında değişikliğe yol açmaktadır. 


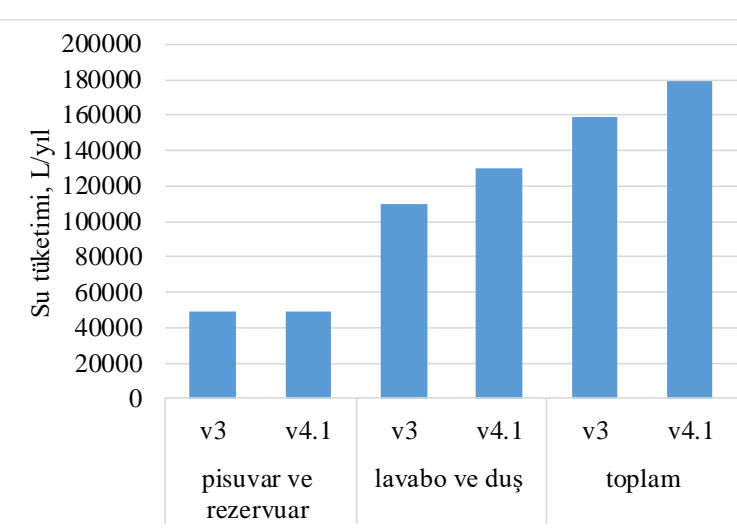

Şekil 2. Sifon ve armatürlerdeki yıllık su tüketimi

Şekil 3'te belirtildiği üzere, LEED v3 BD+C'ye göre binada ylllk olarak 158866,5 litrelik su tüketilmektedir. Aynı binanın Tablo 1'de verilen baz değerlere göre hesaplanan su tüketimi miktarı ise 281232,9 litre/yıl'dır. Dolayısıyla çalışmadaki örnek binada, LEED v3 BD+C baz değerlerine göre \%43 oranında su verimliliğgi sağlanmaktadır. V4.1 kapsamında incelenen ofis binasındaki su tüketimi 179318,1 litre/yıl iken v4.1 baz değerlerine göre yıllık toplam su tüketimi 281326,5 litre olarak hesaplanmıştır. V4.1'e göre \%36 su verimliliği sağlandığı belirlenmiştir.

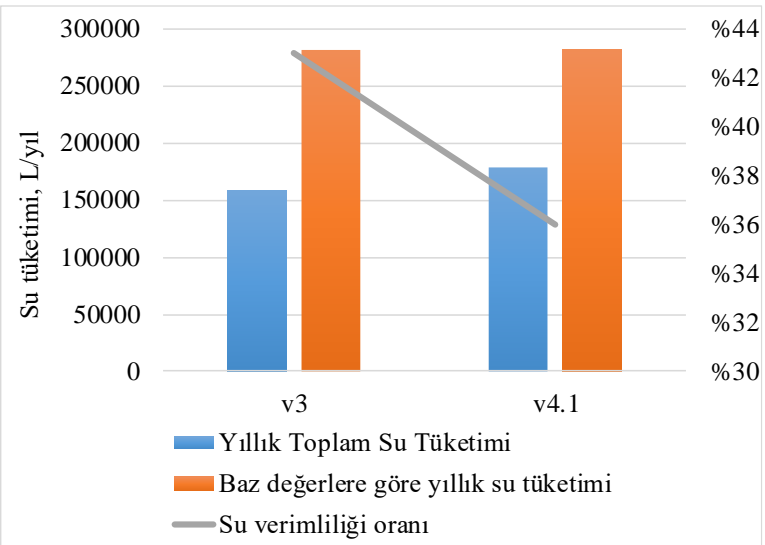

Şekil 3. LEED v3 ile v4.1'deki toplam su tüketim miktarları ve su verimliliği oranları

LEED v3 ile v4.1 arasında, sağlanan su verimlilik oranlarına göre alınabilecek puanlarda da değişiklik olmuştur. V3'te $\% 30, \% 35, \% 40$ su verimliliği sağlanırken sırasıyla 2,3 ve 4 puan alınabilmektedir. V4.1'de ise $\% 25, \% 30, \% 35, \% 40, \% 45, \% 50$ su verimliliği sağlanırken sırasıyla $1,2,3,4,5,6$ puan alınabilmektedir $[12,17]$. Örnek bina için v3' e göre yapılan hesaplamada, \%43 su verimliliği ile birlikte ilgili krediden 4 puan alınabildiği görülürken aynı bina, v4.1'deki gereklilikler kapsamında analiz edildiğinde binada $\% 36$ su verimliliği sağlandığı ve bunun 3 puana tekabül ettiği görülmektedir.

LEED, puanlama üzerinden sertifika seviyesinin belirlendiği bir sertifikasyon sistemi olduğu için kredilerden alınacak puanlar önem arz etmektedir. Güncellenen versiyonda iç mekândaki su kullanımın azaltılmasıyla ilgili krediden v3'e göre aynı puanı alabilmek için mevcutta kullanılan rezervuar ve vitrifiye armatürlerinden $\% 10,5$ oranında daha az su tüketimi olanların tercih edilmesi gerekmektedir.

Suyun kullanılır hale getirilmesi, dağıtımı, atık suyun arıtılması gibi konular sera gazı emisyon salımına neden olduğundan, su kullanımının azaltılması sera gazı emisyonu açısından da fayda getirmektedir [19]. Ecoinvent'in 2018 verilerine göre 1 litre suyun arıtılmasından başlanarak bertarafina kadar olan yaşam döngüsü içerisinde sebep olduğu $\mathrm{CO}_{2}$ emisyonu 0,367 gramdır [20]. $\mathrm{Bu}$ veriden hareketle yapilan hesaplamalara göre, LEED v3 kapsamında binadaki su tüketim miktarının sebep olduğu $\mathrm{CO}_{2}$ emisyonu yıllık 58,3 kg'dır. Aynı binanın LEED v4.1'de v3 ile aynı verimlilik oranına sahip olabilmesi için tüketmesi gereken su miktarının sebep olacağı $\mathrm{CO}_{2}$ emisyonu ise yıllık 52,1 kg'dır.

Su kullanımının öneminin git gide daha da anlaşıldığı bu dönemlerde, bazı ülkeler kişi başına günlük olarak tüketilmesi beklenen su miktarıyla ilgili hedefler oluşturmuşlardır. Avrupa ülkelerinden İngiltere, 2030'a kadar kişi başına günlük $120 \mathrm{~L}$ su tüketimini gerçekleştirebilmeyi hedeflemiştir [21]. Çalışma binamızda LEED v4.1'e göre günlük kişi başına tüketilen su miktarı 17,7 L olarak hesaplanmıştır. Bir kişinin günün 10 saatini bu ofiste geçirdiği düşünüldüğünde, geriye kalan vakitte geçirdiği mekânlarda, verimli armatür tercihleriyle birlikte 120 L'nin daha da altında su tüketimi sağlanması mümkün olabilir.

$\mathrm{Su}$, binaların operasyonu sırasında en çok kullanılan doğal kaynaklardan olduğu ve $\mathrm{CO}_{2}$ salımına sebep olduğu için LEED'in v4.1'de yaptığı değişiklik ile projelerde su kullanımın azaltılması teşvik edilmektedir [22]. Bu nedenle projeler ya daha düşük debili armatürler ve rezervuar tercihinde bulunmaya, ya da alternatif su kaynaklarından yağmur suyu, gri su gibi kullanımlara yönlendirilmektedir. Su kaynaklarının yalnızca \%3'ünün tatlı su olduğu ve bunun da üçte ikisinin buzullarda olduğu düşünülürse, suyun korunması ve geri dönüşümünün sağlanmasının ne denli önemli olduğu anlaşılmaktadır [21].

\subsection{Enerji Performansının Optimizasyonu}

LEED'in farklı versiyonları olan v3 ile v4.1'in enerji verimliliği kapsamındaki değişiklikleri, örnek bina üzerinde analiz edilmiştir. Bu çalışma kapsamında versiyon özelinde kullanılan ASHRAE standardı ve bu standardın enerji tüketim kalemleri üzerinde, baz bina için ne gibi farklılıklar oluşturduğu tespit edilmiştir. Aynı zamanda bu farklılıkların baz binadaki toplam enerji tüketimi ve binanın toplam enerji verimliliğini nasıl değiştirdiği analiz edilerek, sertifika adayı binaların enerji verimliliği konusunda nasıl 
yönlendirildiği ve bu durumun karbondioksit emisyonlarında ne gibi etkileri olduğu ortaya konulmuştur.

Şekil 4'te görüldüğü üzere; LEED v4.1'de minimum $\% 2$, v3'te ise $\% 8$ enerji verimliliği sağlanması halinde söz konusu krediden puan alınmaya başlanmaktadır. V4.1'de v3'e göre daha düşük verimlilik oranı ile puan alınmaya başlanabilmektedir ancak, verimlilik hesaplarında ASHRAE 90.1-2016 kullanıldığında v3'e göre daha düşük verimlilik oranları elde edilmektedir. V3'te her \%2 verimlilik artışıyla birlikte lineer bir şekilde puan artışı sağlanırken, v4.1'de her \%5 verimlilik artışıyla birlikte alınabilecek puan da artmaktadır. V4.1'de enerji modellemesinden alınabilecek maksimum puan 9 puana düşürülerek, toplam 18 puandan geri kalan 9 puanın sera gazı emisyon değeri sonucuna göre hesaplanması enerji modellemesinin öneminin azaldığı anlamına gelmemektedir. Bir binadaki emisyon salımına o binadaki cihaz seçimlerinin büyük bir oranda etkisi bulunmaktadır. Uluslararası Enerji Ajansı, binalarda verimli sistemler kullanılmasıyla birlikte 30 yıl içerisinde binaların mevcutta sebep olduğu karbon emisyonlarının \%83 oranında azalabileceğini belirtmektedir [23]. Çalışmamızda elde ettiğimiz bulgular ile, v4.1'de dikkate alınan ASHRAE 90.12016, 2007'ye göre baz binalarda çok daha az enerji tüketimi öngörmekte, bu sebeple aynı binanın, v4.1'de v3'e oranla daha düşük enerji verimlilik oranına sahip olduğu ortaya çıkmaktadır.

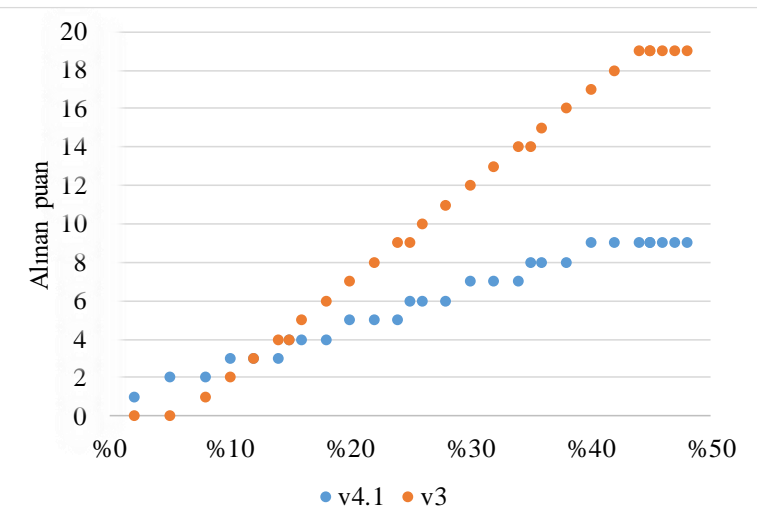

Şekil 4. Enerji modellemesi sonucunun LEED v3 ile v4.1 puanına etkisi

Mekanik bileşenlerin modellenmesi sonucunda her bir bileşen için LEED v3 ile v4.1'deki verimlilik oranları ve enerji tüketim verileri Şekil 5 'te gösterilmektedir. İç aydınlatma, ısıtma, soğutma ve fanlar gibi iki versiyon arasında baz bina verilerinin değişkenlik gösterdiği ekipmanlarda, v4.1'deki verimlilik oranlarının v3'e kıyasla daha düşük olduğu belirlenmiştir. En büyük farkın ise yaklaşı1k \%40'lı bir oranla soğutma sisteminden kaynaklandığı görülmektedir. McKibbin ve Wilcoxen'e göre gün geçtikçe isıtma sistemlerine olan talep azalacak, soğutma sistemleri üzerinde daha fazla talep oluşacaktır [24]. ASHRAE 90.1-2016' da da bu yaklaşımın etkisi olduğu görülmekte ve soğutma sistemleri üzerinde 1sıtmaya göre daha katı gereklilikler oluşturularak projeler daha verimli soğutma sistemleri tercih etmeye yönlendirilmektedir. Kullanım sıcak suyu ve dış aydınlatma için v3 ile v4.1'deki baz değerler aynı kaldığından, bu iki bileşende versiyon değişimi bir farklılığa sebep olmamıştır. Priz yükleri için ise, proje binasındaki tüketim değeri baz binada da aynı seviyede $(9,6 \mathrm{~kW})$ girildiği için her iki versiyonda da proje binasındaki priz yüklerinin baz binaya oranında değişiklik oluşmamıştır.

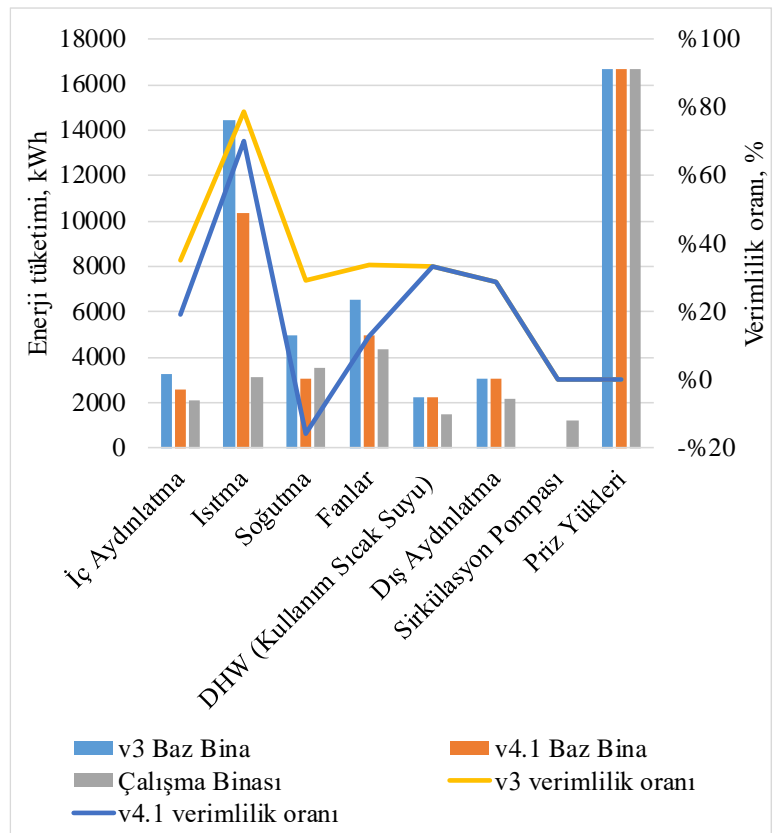

Şekil 5. LEED v3 ile v4.1'deki mekanik bileşenlerin verimlilik yüzdeleri ile enerji modellemesi tüketim sonuçları

Mekanik bileşenlerin toplam enerji verimliliği içerisindeki oranları dikkate alındığında LEED v3 ile v4.1'de ortak olarak ısıtma sistemlerinin tüm bileşenler arasında sırasıyla $\% 68$ ve $\% 87$ verimlilikle en yüksek paya sahip oldukları görülmektedir (Şekil 6). Bunun sebebi çalışma binasındaki 1sıtma sistemleri için ASHRAE'nin önerdiği cihaz özelliklerine göre daha verimli sistemlerin tercih edilmiş olmasıdır. Soğutma sisteminin LEED v4.1'de, sirkülasyon pompalarının ise her iki versiyonda toplam verimliliğe negatif etki yaptığı görülürken priz yüklerinin bir etkisi olmadığ1, diğer bileşenlerin $\% 5$ ile $\% 13$ arasında değişen etkiye sahip oldukları görülmektedir. 


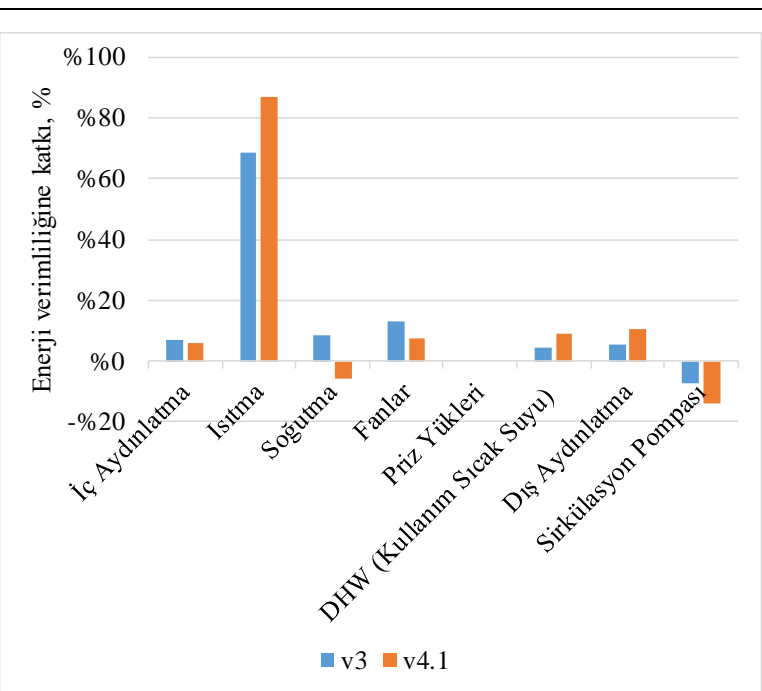

Şekil 6. LEED v3 ve v4.1'de mekanik bileşenlerin toplam verimliliğe katkıları

v3 ve v4.1 için Carrier HAP modelleme programı ile elde edilen toplam enerji tüketimi, enerji maliyetleri ve verimlilik oranları Tablo 3'te verilmektedir. Çalışma binasında 9610,4 kW'lık enerji üretimi PV panel kullanımıyla sağlanmaktadır. Carrier HAP programında PV panelden sağlanan enerji üretimi bir girdi olarak işlenemediği için, nihai enerji verimliliği sonucunu ortaya koyabilmek amaciyla Tablo 3'te belirtilen değerlere PV panelden üretilen enerji miktarı daha sonra işlenmiştir.

Tablo 3. PV panel enerjisi katılmadan v3 ile v4.1 enerji modellemesi toplam sonuçları

\begin{tabular}{|c|c|c|c|c|c|}
\hline & Baz Bin & (BB) & $\begin{array}{r}\text { Çalışma } \\
\text { (ÇI }\end{array}$ & $\begin{array}{l}\text { Binası } \\
\text { ) }\end{array}$ & $\begin{array}{c}\text { Verimlilik } \\
\text { Oranı } \\
\text { (v3 } \\
\text { verimlilik }\end{array}$ \\
\hline & $\begin{array}{c}\text { Enerji } \\
\text { Kullanımı } \\
(\text { kWh })\end{array}$ & $\underset{(\$)}{\text { Maliyet }}$ & $\begin{array}{c}\text { Enerji } \\
\text { Kullanımı } \\
(\mathbf{k W h})\end{array}$ & $\begin{array}{c}\text { Maliyet } \\
(\$)\end{array}$ & $\begin{array}{c}\text { Enerji } \\
\text { Verimi (\%) }\end{array}$ \\
\hline v3 & $51.114,30$ & 7.667 & $34.557,30$ & 5.184 & $\% 32,40$ \\
\hline v4.1 & $42.920,40$ & 6.438 & $34.557,30$ & 5.184 & $\% 19,50$ \\
\hline
\end{tabular}

ASHRAE 90.1 standardı, binadaki enerji tüketen cihazların tasarımını yönlendiren ve enerji tüketimlerini değerlendiren standart olduğundan, binadaki enerji verimliliği miktarına direkt olarak etki etmektedir. Bu sebeple ASHRAE 90.1-2016'da belirlenen tüketim değerleri dikkate alınarak yapılan tasarımlar, önceki versiyonlara göre tasarlanmış binalardan daha az enerji tüketen binalar olmaktadır. Güncel versiyonda talep edilen enerji tüketimi eski versiyonlara göre daha düşük olduğu için, aynı bina ASHRAE 90.1-2007 ve 2016 değerleri ile kıyaslandığında enerji verimlilik oranı 2016'da düşmektedir.
Çalışma binasında yıllık olarak 34.557,30 kW'lık enerji tüketimi mevcuttur. Tüketilen bu enerjinin 9.610,4 kW'lık kısmı PV paneldeki enerjiyle sağlandığı için bina şebekeden $24.946,9 \mathrm{~kW}$ enerji tüketmektedir. Enerji verimliliği Eşitlik 1'deki gibi hesaplandığında, binadaki toplam enerji verimliliği v3'teki baz binaya göre $\% 51$; v4.1'deki baz binaya göre ise $\% 41,8$ olarak hesaplanmaktadır. Yani versiyonların temel aldı̆̆ ASHRAE 90.1 standardındaki iç aydınlatma, 1sıtma, soğutma ve fanlarda beklenen enerji verimlilik değerleri v4.1'de daha yükseldiği için, aynı verimlilik hesap yöntemi kullanıldığında v4.1'e göre enerji verimlilik oranının düştüğü gözlemlenmektedir. Ayrıca 1sıtma ve soğutma sistemleri, binadaki doğrudan emisyon kaynaklarının başında geldiği için v4.1'deki bu değişiklikler $\mathrm{CO}_{2}$ emisyon salımını olumlu yönde etkilemektedir [25].

Fakat LEED v4.1'de enerji performansının optimizasyonu kredisindeki verimlilik hesap yöntemi de ASHRAE 90.1'e göre güncellenmiştir. V4.1'deki nihai sonucu elde etmek amaciyla Eşitlik 2 kullanılmıştır. Buna göre hem binadaki enerji verimliliği hem de bu eşitlikteki maliyet kalemlerinin yerine sera gazı emisyon faktörü koyularak hesaplanan sera gazı emisyon salım oranı $\% 23$ 'tür.

Çalışma binasının LEED v3 ile v4. 1 baz binalarına göre $\% 50$ daha az elektrik tüketmeleri için v3'e göre $25.557,15 \mathrm{kWh}, \mathrm{v} 4.1$ 'e göre 21.460,2 kWh elektrik tüketimi olmalıdır. İklim Şeffaflığ (Climate Transparency) küresel birliğinin Kahverengiden Yeşile 2019 (Brown to Green 2019) raporunda, Türkiye'deki her bir $\mathrm{kWh}$ elektrik üretimi için $481 \mathrm{gCO}_{2}$ salımı olduğu ortaya konulmuştur [26]. Bu veriden hareketle, aynı verimlilik oranı için v3'te yıllık olarak $1,2 \mathrm{E}+04 \mathrm{~kg}$ $\mathrm{CO}_{2}$ salımı olurken v4.1'de $1 \mathrm{E}+04 \mathrm{~kg} \mathrm{CO}_{2}$ salımı olacağı tespit edilmiş̧tir.

$\mathrm{Bu}$ verimlilik oranlarına göre aynı bina LEED $\mathrm{BD}+\mathrm{C}$ v3 kapsamında değerlendirildiğinde, krediden alınabilecek en yüksek puanı (19 puan) alabilmektedir. v4.1 kapsamında ise enerji modellemesi sonucuna göre enerji verimliliğinden 5 puan, sera gazı emisyon salımından 4 puan alarak toplam 9 puan elde edebilmektedir. Burada v4.1'de hem takip edilen standardın katılaştığı, hem de projelerde daha da yüksek verimlilik oranlarına erişilmesi için puanlama sisteminin değiştiği görülmektedir.

\section{SONUC VE DEĞERLENDİRMELER}

LEED BD+C:NC kapsamında versiyon 3 ile versiyon 4.1 arasındaki farklar incelendiğinde öncelikle temel olarak, yapılan güncellemelerin kullanıcıları daha az su ve enerji tüketmeye yönlendirme amaçlı olduğu tespit edilmiştir. LEED yeşil bina sertifika sisteminde sertifikayı alabilmek ve sertifika seviyesini yükseltebilmek için kredilerden alınan puanlar oldukça önemlidir. Bu sebeple LEED, yaptığı güncellemeleri 
hem kriterler hem de alınabilecek puanlar üzerinden gerçekleştirmiştir. Puan sistemi üzerindeki değişikliğin amacı, proje sahiplerini daha yüksek puan alabilmeleri için daha az su ve enerji tüketmeye, bu tüketimden $\begin{array}{lll}\text { kaynaklı } & \mathrm{CO}_{2} & \text { emisyonlarını azaltmaya }\end{array}$ yönlendirmektir.

V4.1'de enerji performansının optimizasyonu kredisinden alınabilen maksimum 18 puanın, ikiye bölünerek enerji verimliliği ve sera gazı emisyon salımı olarak analiz edilmeye başlanması, son yıllarda dünyadaki sera gazı salımlarının artışı dolayısıyla inşaat sektöründe bu konuya dikkat çekilmesi ve sektörün yönlendirilmesi açısından önemlidir. Aynı konu su verimliliği için de geçerlidir. Su kullanımının azaltılması, doğal kaynağın tüketilmesinin yanında sera gazı salımlarında da etkili olduğu için LEED, inşaat projelerini daha az su tüketimi için yönlendirmektedir. $\mathrm{Bu}$ çalışmayla birlikte, elektrik tüketiminden kaynaklanan $\mathrm{CO}_{2}$ emisyon salımlarının önemi kadar, sonlu bir kaynak olan suyun bina kullanımı için temini ve atık suyun arıtılmasından kaynaklı atmosfere salınan $\mathrm{CO}_{2}$ miktarının da yeşil bina sertifikaları üzerindeki önemi anlaşılmıştır. Çalışma binasının LEED v3 ile v4.1 baz binalarına göre $\% 50$ enerji verimlilik oranına sahip olabilmesi için v4.1'de binanın v3' e göre yıllık olarak $2000 \mathrm{~kg}$ daha az $\mathrm{CO}_{2}$ salımının olmas1 gerekmektedir. Aynı binanın LEED v4.1 su verimliliği kriterlerince v3'e göre karbon salımının \%13 oranında daha yüksek hesaplanacağı öngörülerek su tüketiminin sınırlandırılması gerekmektedir.

$\mathrm{Bu}$ çalışmayla aynı zamanda, yenilenebilir enerji kaynak kullanımının binalardaki enerji verimliliğine ne denli katkı sağladığı ortaya konmuştur. Çalışma binasında yenilenebilir enerji kaynağı kullanılmadan önce v3'e göre $\% 30,40$, v4.1'e göre $\% 19,50$ enerji verimliliği sağlanıyorken, PV panel kullanımıyla birlikte bu oranlar sirasiyla $\% 51$ ve $\% 41,8$ 'e yükselmiştir.

\section{TEŞEKKÜR}

Data temini ve enerji modellemesindeki desteklerinden ötürü ERKE Sürdürülebilir Bina Tasarım ve Danışmanlık ekibine teşekkürler.

\section{KAYNAKLAR}

[1] Kılıç, C. (2009). Küresel İklim Değişikliği Çerçevesinde Sürdürülebilir Kalkınma Çabaları ve Türkiye. C.Ü. İktisadi ve İdari Bilimler Dergisi, 10(2), 19-41.

[2] Houghton, J. (2009). Global Warming: The Complete Briefing. Cambridge University Press.

[3] Karakaya, E., \& Özcağ, A. G. M. (2001). Sürdürülebilir Kalkınma ve İklim Değişikliği: Uygulanabilecek İktisadi Araçların Analizi. In First Conference in Fiscal Policy and Transition Economies, University of Manas.

[4] Saka, İ. (2011). Sürdürülebilirlik Açısından İstanbul'da bir Ofis Binasının Leed Sertifikalandırma
Sistemi Kapsamında Değerlendirilmesi. Yüksek Lisans Tezi, İstanbul Teknik Üniversitesi, Türkiye.

[5] Rastogi, A., Choi, J. K., Hong, T., \& Lee, M. (2017). Impact of Different LEED Versions for Green Building Certification and Energy Efficiency Rating System: A Multifamily Midrise Case Study. Applied energy, 205, 732-740.

[6] USGBC, https://www.usgbc.org/projects, (Nisan 2020).

[7] Awadh, O. (2017). Sustainability And Green Building Rating Systems: LEED, BREEAM, GSAS and Estidama Critical Analysis. Journal of Building Engineering, 11, 25-29.

[8] Anbarci, M., Giran, O., \& Demir, I. H. (2012). Uluslararasi Yesil Bina Sertifika Sistemleri İle Türkiye'deki Bina Enerji Verimliligi Uygulamasi. EJournal of New World Sciences Academy NWSA Engineering Sciences, 7(1), 158-176.

[9] Suzer, O. (2019). Analyzing The Compliance And Correlation of LEED and BREEAM By Conducting a Criteria-Based Comparative Analysis and Evaluating Dual-Certified Projects. Building and Environment, 147, 158-170.

[10] Sachdeva, S. (2016). An Introduction to LEED. Heapy Engineering presentation.

[11] USGBC, https://new.usgbc.org/leed-v41\#bdc (Eylül 2019).

[12] USGBC. (2019). LEED BD+C 4.1 Guide. 1. Bask1 [13] Schwartz, Y., \& Raslan, R. (2013). Variations in Results of Building Energy Simulation Tools, and Their Impact on BREEAM and LEED ratings: A case study. Energy and Buildings, 62, 350-359.

[14] Varma, C. S., \& Palaniappan, S. (2019). Comparision of Green Building Rating Schemes Used in North America, Europe and Asia. Habitat International, 89, 101989.

[15] Liu, Z., Zhang, C., Guo, Y., Osmani, M., \& Demian, P. (2019). A Building Information Modelling (BIM) based Water Efficiency (BWe) Framework for Sustainable Building Design and Construction Management. Electronics, 8(6), 599.

[16] ASHRAE, A. S. (2007). Standard 90.1-2007: Energy Standard for Buildings Except Low-Rise Residential Buildings. American Society of Heating, Refrigerating, and Air-Conditioning Engineers, Inc. Atlanta, Georgia, USA.

[17] USGBC. (2009). LEED V3 Referance Guide for Building Design and Construction. 1. bask1, s.165-177 [18] Elektrik Birim Fiyat, https://gazelektrik.com/enerji-piyasalari/elektrik-

fiyatlari (Mart 2020).

[19] Greer, F., Chittick, J., Jackson, E., Mack, J., Shortlidge, M., \& Grubert, E. (2019). Energy And Water Efficiency in LEED: How Well are LEED Points Linked to Climate Outcomes?. Energy and Buildings, 195, 161-167.

[20] Ecoinvent 3.4 (2018), Market for tap water, verified.

[21] Zhang, Y., Wang, J., Hu, F., \& Wang, Y. (2017). Comparison Of Evaluation Standards For Green 
Building İn China, Britain, United States. Renewable and Sustainable Energy Reviews, 68, 262-271.

[22] Al-Qawasmi, J., Asif, M., El Fattah, A. A., \& Babsail, M. O. (2019). Water Efficiency and Management in Sustainable Building Rating Systems: Examining Variation in Criteria Usage. Sustainability, 11(8), 2416.

[23] Becqué, R., Mackres, E., Layke, J., Aden, N., Managan, K., Nesler, C., \& Graham, P. (2016). Accelerating Action Efficient Buildings: A Blueprint for Green Cities.
[24] Kılıç, C. (2009). Küresel İklim Değişikliği Çerçevesinde Sürdürülebilir Kalkınma Çabaları ve Türkiye. C.Ü. Íktisadi ve İdari Bilimler Dergisi, 10, 19-41. [25] Dean, B., Dulac, J., Petrichenko, K., \& Graham, P. (2016). Towards zero-emission efficient and resilient buildings.: Global Status Report.

[26] Climate Transparency (2019). Brown to Green Report: The G20 Transition Towards A Net-Zero Emissions Economy. 